Check for updates

Cite this: J. Mater. Chem. C, 2021, 9, 1972

\section{Triphenylamine- and triazine-containing hydrogen bonded complexes: liquid crystalline supramolecular semiconductors $\dagger$}

\author{
Beatriz Feringán, (D) ${ }^{a}$ Roberto Termine, (D) ${ }^{b}$ Attilio Golemme, (D) *b \\ José M. Granadino-Roldán, (iD c Amparo Navarro, (D) *c Raquel Giménez (iD *a and \\ Teresa Sierra iD *a
}

\begin{abstract}
Despite the fact that triphenylamine derivatives have been widely explored as hole-transporting materials, studies on charge transport properties in the liquid crystal phase have been overlooked. Here, it is reported that triphenylamine liquid crystals can attain very high hole mobility values in a hexagonal columnar mesophase, up to $\mu \approx 5 \mathrm{~cm}^{2} \mathrm{~V}^{-1} \mathrm{~s}^{-1}$. The columnar liquid crystalline phase was obtained by a proper design of a supramolecular mesogen, and this is unprecedented for triphenylamine liquid crystals. In fact, the supramolecules were formed by hydrogen-bonded 1:3 complexes of a star-shaped triazine core and three triphenylamine peripheral units. The resulting hexagonal columnar mesophase acts as a successful scaffold that confines TPA units at the periphery of columns. Challenging DFT theoretical investigations into a model based on such supramolecular systems involving a large number of atoms were undertaken to explore the stability and geometry of the complexes and their electronic properties.
\end{abstract}

Received 3rd November 2020, Accepted 5th January 2021

DOI: $10.1039 / \mathrm{dOtc05186a}$

rsc.li/materials-c

\section{Introduction}

As a paradigm of assemblies with order-dependent properties, liquid crystals (LCs) constitute a successful tool to engineer the assembly of appropriately designed molecules and implement novel functional materials. ${ }^{1}$ Among the different LC organizations, columnar mesophases ${ }^{2}$ are of special interest because of their 1D nanostructured architecture, which makes them interesting for charge transport and semiconducting behavior. ${ }^{3}$

Because of its electroactive and photoactive properties, triphenylamine shows up as a valuable unit to challenge its inclusion in columnar liquid crystalline architectures with improved charge-carrier mobility. On the one hand, triphenylamine, TPA, has a strong electron-donor character. The hole mobility values

\footnotetext{
${ }^{a}$ Instituto de Nanociencia y Materiales de Aragón (INMA), Departamento de Química Orgánica, Facultad de Ciencias, CSIC-Universidad de Zaragoza, 50009-Zaragoza, Spain. E-mail: rgimenez@unizar.es, tsierra@unizar.es

${ }^{b}$ LASCAMM CR-INSTM, CNR-NANOTEC SS di Rende, Dipartimento di Fisica, Università della Calabria,87036 Rende, Italy.E-mail: attilio.golemme@unical.it ${ }^{c}$ Departamento de Quimica Física y Analítica, Facultad de Ciencias Experimentales, Universidad de Jaén, Campus Las Lagunillas, 23071 Jaén, Spain.

E-mail: anavarro@ujaen.es

$\dagger$ Electronic supplementary information (ESI) available: Synthetic procedures, chemical characterization data, liquid crystalline properties, electrochemical studies, charge mobility measurements, theoretical characterization. See DOI: 10.1039/d0tc05186a
}

measured in amorphous films of TPA derivatives are usually in the range $10^{-5}-10^{-2} \mathrm{~cm}^{2} \mathrm{~V}^{-1} \mathrm{~s}^{-1}$. ${ }^{4-14}$ Accordingly, TPA has been widely used in the design of molecules that provide materials for hole injection and hole transport layers in optoelectronic devices, ${ }^{4}$ such as OLEDs, ${ }^{15}$ OFETs,${ }^{16}$ or solar cells. ${ }^{5,6,17,18}$ On the other hand, TPA adopts a propeller shape in which the phenyl rings are rotated by around $41^{\circ}$ with respect to the plane defined by the three $\mathrm{N}-\mathrm{C}$ bonds. ${ }^{19,20}$ This is the reason why TPA usually promotes amorphous glasses with good film-forming properties and this favors its inclusion in materials for thermodynamically stable optoelectronic devices. ${ }^{15,21}$ Nevertheless, there are outstanding studies that concern the possibility of employing TPA as a structural unit to obtain ordered supramolecular architectures, ${ }^{22}$ thus leading to enhanced conductivity in the aggregate. ${ }^{23}$ In this respect, it has been proven that some TPAderivatives containing amide groups aggregate in solvents to form supramolecular polymers with chirality amplification, ${ }^{24-27}$ photoinduced self-assembly due to the formation of radical cation species in the presence of chlorinated solvents, ${ }^{24,28}$ or supramolecular electropolymerization. ${ }^{29}$ However, few examples have been described in which TPA is part of a mesogen that arranges in a columnar LC phase. ${ }^{30-33}$ In addition, charge transport properties in the LC phase have not been reported to date.

In the route from a molecule, i.e. TPA, to a functional LC material, the correct design of constituent molecules is essential but also the control of intermolecular interactions responsible 


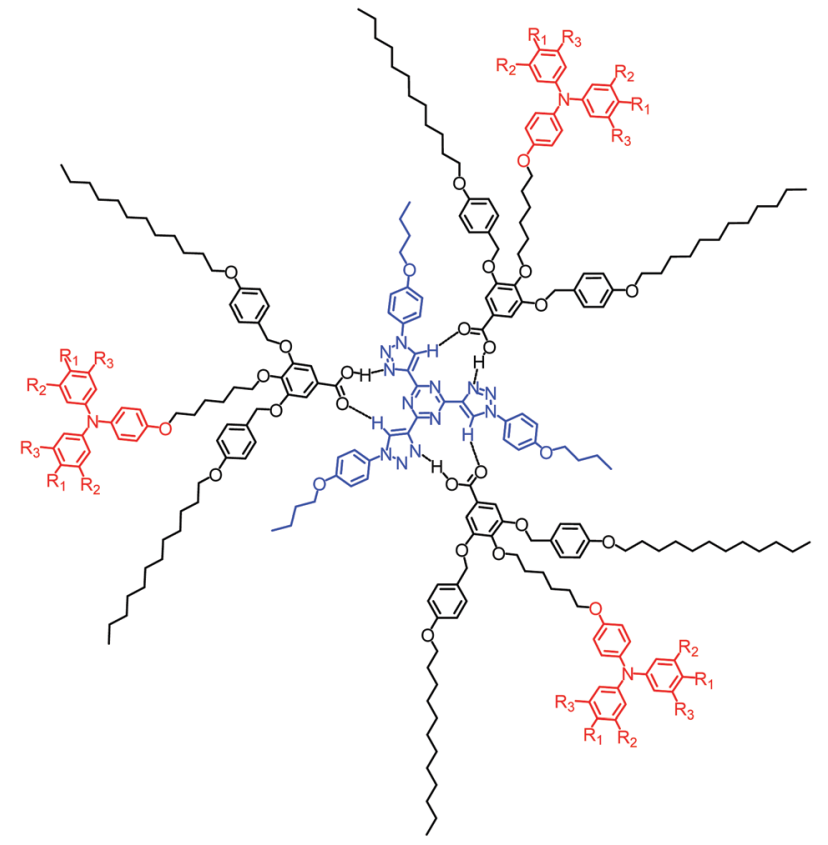

$$
\begin{array}{ll}
\text { T3C }_{4}-\text {-BnOC }_{12}-\text { TPA2C }_{12} & \mathrm{R}_{1}=\mathrm{OC}_{12} \mathrm{H}_{25}, \mathrm{R}_{2}=\mathrm{R}_{3}=\mathrm{H} \\
\text { T3C }_{4}-\text { - BnOC }_{12}-\text { TPA4C }_{12} & \mathrm{R}_{1}=\mathrm{R}_{2}=\mathrm{OC}_{12} \mathrm{H}_{25}, \mathrm{R}_{3}=\mathrm{H} \\
\text { T3C }_{4}-2 \text { BnOC }_{12}-\text { TPA6C }_{12} & \mathrm{R}_{1}=\mathrm{R}_{2}=\mathrm{R}_{3}=\mathrm{OC}_{12} \mathrm{H}_{25}
\end{array}
$$

Fig. 1 Chemical structure of the three $\mathrm{H}$-bonded complexes formed by $\mathrm{T}_{3} \mathrm{C}_{4}$ and three triphenylamine-containing benzoic acids with different number of peripheral dodecyloxy chains.

for the supramolecular architecture and the properties. ${ }^{34-36}$ In this respect, a myriad of mesogens have been built through hydrogen-bonding interactions between complementary units, thus forming defined supramolecules that, in turn, self-organize into a mesophase architecture. Such a possibility provides an efficient bottom-up methodology to attain hierarchically organized supramolecular materials based on LCs, ${ }^{37-39}$ and yield successfully supramolecular semiconductors. ${ }^{40,41}$

In order to prepare TPA-containing semiconductors we designed a hydrogen bonded complex formed by two complementary units, a star-shaped triazine, $\mathbf{T}_{3} \mathbf{C}_{\mathbf{4}}$ (blue in Fig. 1), and three benzoic acid derivatives bearing the TPA unit, $\mathbf{A}-\mathbf{2 B n O C}_{\mathbf{1 2}^{-}}$ TPAnC $_{12}(n=2,4,6)$, (Fig. 1). As for the acid, the high tendency of 3,4,5-tris(4-alkoxybenzylozy)benzoic acids to promote the formation of columnar liquid crystalline organizations on their own, ${ }^{42}$ and particularly forming $1: 3$ complexes with $\mathbf{T} 3 \mathbf{C}_{4},{ }^{39 d, e}$ inspired us to design the acids $\mathbf{A}-\mathbf{2} \mathbf{B n O C}_{\mathbf{1 2}}$ - $\mathbf{T P A n C}_{\mathbf{1 2}}(n=2,4,6)$. The aim was to ensure the stability of the complexes and compensate for the lack of planarity of TPA, which could disturb the stacked arrangement. Thus, three complexes were prepared and characterized, and their $\mathrm{LC}$ behaviour studied. Charge mobility measurements were carried out on $\mathbf{T}_{3} \mathbf{C}_{4}-\mathbf{2} \mathbf{B n O C}_{\mathbf{1 2}}$ TPA2C $_{12}$, which showed a hexagonal columnar mesophase that was stable at room temperature. DFT theoretical calculations were also undertaken in a model system to explore the stability and geometry of the new supramolecules, their electronic properties and the main parameters that control the charge transport. The theoretical analysis of a proposed new molecular material is playing an ever-increasing role in research. Although the comparison between theoretical and experimental results might not be straightforward, ${ }^{43}$ it highlights trends and explains the measured properties from an electronic point of view. Here, it is worth emphasizing that the size of the theoretical model applied here (402 atoms, which in the calculation of the transfer integral required a dimer of 804 atoms) exceeded, to the best of our knowledge, previous theoretical studies on LCs, ${ }^{44}$ and involved a significant challenge.

\section{Results and discussion}

\section{Synthesis and characterization}

The triazine core, $\mathbf{T} 3 \mathbf{C}_{\mathbf{4}}$, was synthesized by a previously reported procedure. ${ }^{39 d}$ The synthesis of acids $\mathbf{A}-\mathbf{2} \mathbf{B n O C}_{\mathbf{1 2}^{-}}$ TPA2C $_{12}$ (11a), A-2BnOC $12^{-T_{P A 4 C}}$ (11b) and A-2BnOC $_{12^{-}}$ TPA6C $_{12}$ (11c) is presented in Scheme 1. The acids consist of a triphenylamine moiety and a 3,5-dibenzyloxybenzoic acid moiety linked together by a flexible $n$-hexamethylene spacer. The triphenylamine moiety $\mathbf{4 a - c}$ was synthesized in high yields, ca. $80 \%$, by a Buchwald-Hartwig C-N coupling ${ }^{45}$ between parabenzyloxyaniline (1) and the corresponding aryl halide $3 \mathbf{a}-\mathbf{c} .^{46}$ Benzyl cleavage in 4a-c provided a triphenylamine moiety with a hydroxy group and peripheral dodecyloxy chains (5a-c), with yields around $90 \%$. The introduction of 6-bromohexanol gave rise to the triphenylamine-containing alcohol $\mathbf{6 a - c}$, which was coupled with methyl 4-hydroxy-3,5-bis(tert-butyldimethylsilyloxy)benzoate (7) under Mitsunobu conditions, reaching yields between 55\% and $80 \%$. Subsequent deprotection of the hydroxyl groups at positions 3 and 5 of intermediates 8a-c, using tetrabutylammonium fluoride, gave quantitatively the corresponding derivatives with free hydroxyl groups $(\mathbf{9 a - c})$, which allowed the introduction of the para-dodecyloxybenzyl group ${ }^{47}$ by means of a Williamson reaction and moderate yields, $c a$. $37 \%$. Hydrolysis of the methyl esters 10a-c gave the acid components A-2 $\mathbf{B n O C}_{12}-\mathbf{T P A}_{2} \mathrm{C}_{12}, \mathbf{A}^{-2} \mathbf{B n O C}_{12}-$ TPA4C $_{\mathbf{1 2}}$ and $\mathbf{A}-\mathbf{2} \mathbf{B n O C}_{\mathbf{1 2}} \mathbf{T P A 6 C}_{\mathbf{1 2}}$, with moderate-high yields between $57 \%$ and $71 \%$. Details of the synthesis and characterization of these acids are collected in the ESI. $\dagger$

The supramolecular complexes were prepared by dissolving the components, $\mathbf{T} 3 \mathbf{C}_{4}$ core and the acid, in a $1: 3$ ratio, in dichloromethane and evaporating the solvent. The solutions of the mixtures were prepared in amber-coloured vials to avoid possible oxidation processes of the triphenylamines promoted by light in chlorinated solvents and characterized by NMR (Fig. S2, $\mathrm{ESI}+)^{28}$

A thermal treatment, in which the mixtures were heated to the isotropic liquid state and then allowed to cool down to room temperature, was carried out with the aim of improving the homogeneity and favouring the formation of the supramolecular complexes.

The three complexes were studied by FTIR at room temperature on samples cooled from the isotropic liquid (Fig. 2, and Fig. S3, S4, ESI $\dagger$ ). A comparison between the spectra of the complex $\mathbf{T}_{3} \mathbf{C}_{4}-\mathbf{2 B n O C}_{12}-\mathbf{T P A}_{\mathbf{2}} \mathbf{C}_{\mathbf{1 2}}$ and its two components is 


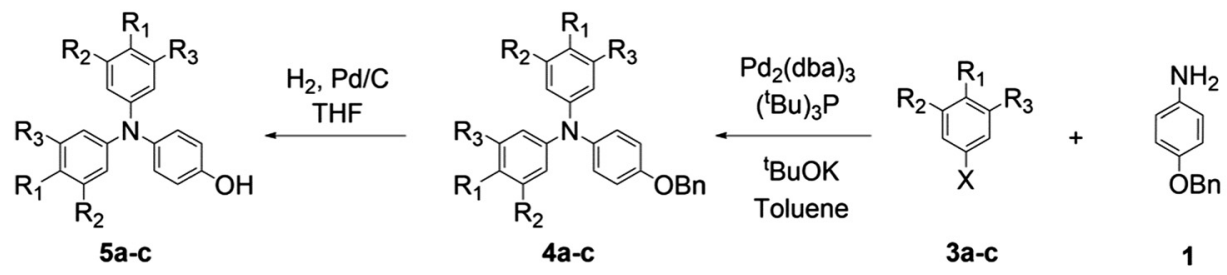<smiles>[R]c1cc(N(c2ccc(OCCCCCO)cc2)c2cc([R])c([R])c([R])c2[R])cc([R])c1[R]</smiles>

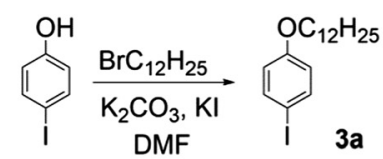

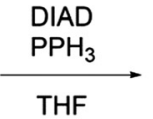

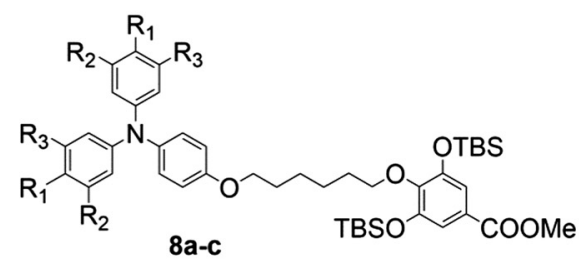<smiles>[R]c1cc(Br)cc([R])c1[R]</smiles>

$$
\begin{aligned}
& \text { a: } R_{1}=O C_{12} H_{25}, R_{2}=R_{3}=H \\
& \text { b: } R_{1}=R_{2}=O C_{12} H_{25}, R_{3}=H \\
& \text { c: } R_{1}=R_{2}=R_{3}=O C_{12} H_{25}
\end{aligned}
$$

3b,c

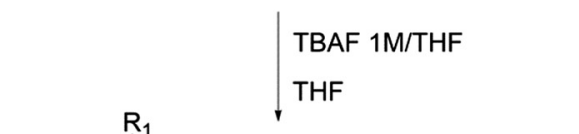<smiles>[R2]c1cc(N(c2ccc(OCCCCCCOc3c(O)cc(C(=O)OC)cc3O)cc2)c2cc([R])c([R])c([R3])c2)cc([R])c1[R2]</smiles>

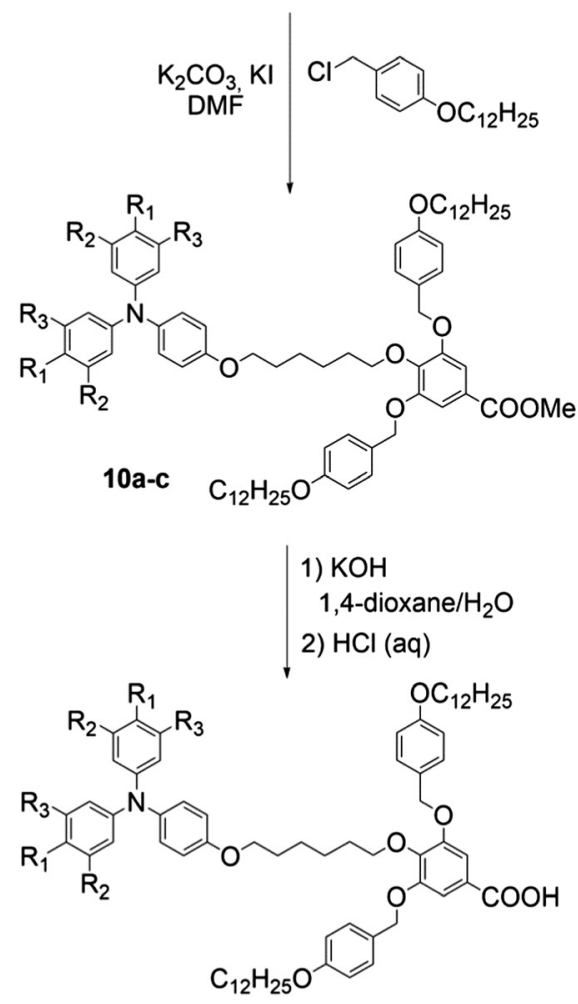

Scheme 1 Synthesis of the acids.

11a: $A-2 B^{2} C_{12}-$ TPA2C $_{12}$ 11b: A-2BnOC 12 -TPA4C $\mathrm{C}_{12}$ 11C: $A-2 B_{12}-$ TPACC $_{12}$

provided in Fig. 2. The spectrum of the supramolecular complex shows bands corresponding to the heterocyclic rings of T3C $_{\mathbf{4}}$ at slightly higher wavenumbers (1569-1573 $\left.\mathrm{cm}^{-1}\right)$ than those in the free core $\left(1566 \mathrm{~cm}^{-1}\right)$. More importantly, the 

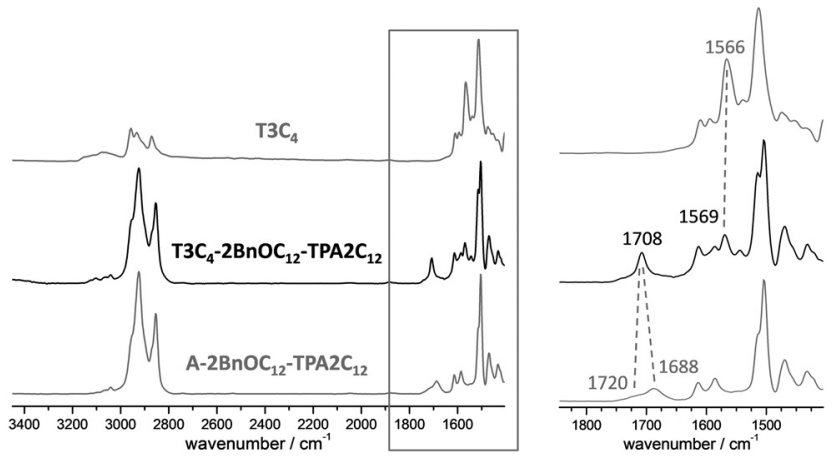

Fig. 2 FTIR spectra measured on $\mathrm{KBr}$ pellets at r.t. of $\mathbf{T 3 C}_{4}$, the acid A-2 $\mathrm{BnOC}_{12}-\mathrm{TPA}_{2} \mathrm{C}_{12}$ and the corresponding supramolecular complex $\mathrm{T}_{3} \mathrm{C}_{4}-2 \mathrm{BnOC}_{12}-\mathrm{TPA}_{2} \mathrm{C}_{12}$

spectrum of the complex shows a $\mathrm{C}=\mathrm{O}$ stretching band at $1708 \mathrm{~cm}^{-1}$ in contrast with the spectrum of the acid that presents a $\mathrm{C}=\mathrm{O}$ stretching band corresponding to the dimeric form at $1688 \mathrm{~cm}^{-1}$, and a shoulder at $1720 \mathrm{~cm}^{-1}$ that can be attributed to the open dimer form of the acid. ${ }^{48}$ These changes are consistent with the formation of the proposed $\mathrm{H}$-bonded complex between $\mathbf{T} 3 \mathbf{C}_{\mathbf{4}}$ and the corresponding acid. ${ }^{39 d, e, 41}$

\section{Liquid crystalline properties}

The thermal properties and liquid crystalline behaviour of the H-bonded complexes were studied by POM, TGA, DSC and X-ray diffraction and the results are collected in Table 1.

All the complexes appeared under the POM as homogeneous materials, which were thermally stable within the liquid crystalline temperature interval as confirmed by thermogravimetric analysis (Fig. S5, ESI $\dagger$ ). The complexes have improved mesomorphic properties with respect to those of the precursor acids (Fig. S6-S9 and Table S1, ESI $\dagger$ ). The acid $\mathbf{A}^{-2} \mathbf{B n O C}_{\mathbf{1 2}}-\mathbf{T P A}_{2} \mathbf{C}_{\mathbf{1 2}}$ showed a hexagonal columnar mesophase, but acids $\mathbf{A}^{-2} \mathbf{B n O C}_{\mathbf{1 2}^{-}}$ TPA4C $_{12}$ and $\mathbf{A}^{-2 B n O C} \mathbf{1 2}_{\mathbf{1 2}}$-TPA6C $_{12}$ showed a complex thermal behavior and their diffractogram contained a few reflections that could not be indexed unequivocally to any defined columnar arrangement (Fig. S10 and Table S2, ESI $\dagger$ ).

All three supramolecular complexes showed textures consistent with columnar mesomorphism when cooled from the isotropic liquid (Fig. 3 and Fig. S11, ESI $\dagger$ ). T3C $_{\mathbf{4}}-\mathbf{2 B n O C}_{\mathbf{1 2}} \mathbf{T P A 2 C}_{\mathbf{1 2}}$ is an enantiotropic liquid crystal that shows a single mesophase that is stable at room temperature, as confirmed by its DSC thermogram (Table 1 and Fig. S12, ESI $\dagger$ ). Although complexes $\mathbf{T 3 C}_{\mathbf{4}^{-}}$ 2BnOC $_{12}$-TPA4C $\mathbf{C}_{12}$ and $\mathbf{T 3 C}_{\mathbf{4}}-\mathbf{- B n O C}_{\mathbf{1 2}}$-TPA6C $\mathbf{C}_{12}$ appeared to be

Table 1 Thermal properties of the supramolecular complexes. Lattice parameters of the corresponding hexagonal columnar mesophase

\begin{tabular}{|c|c|c|}
\hline Complex & $T\left({ }^{\circ} \mathrm{C}\right)\left[\Delta H\left(\mathrm{~kJ} \mathrm{~mol}^{-1}\right)\right]^{a}$ & $\mathrm{Col}_{\mathrm{h}}$ lattice parameter \\
\hline T3C $_{4}-$-BnOC $_{12}-$ TPA2C $_{12}$ & I $37[2.7] \mathrm{Col}_{\mathrm{h}}$ & $a=46.2 \AA$ \\
\hline T3C $_{4}-$-BnOC $_{12}$-TPA4C 12 & I $76[3.7] \mathrm{Col}_{\mathrm{h}}$ & $a=54.3 \AA$ \\
\hline T3C $_{4}-2$ BnOC $_{12}$-TPA6C $_{12}$ & I $50[2.2] \mathrm{Col}_{\mathrm{h}}$ & $a=55.1 \AA$ \\
\hline
\end{tabular}

${ }^{a}$ Phase transitions (I: isotropic liquid, $\mathrm{Col}_{\mathrm{h}}$ : hexagonal columnar mesophase) from the second cooling cycle recorded at a rate of $10{ }^{\circ} \mathrm{C} \mathrm{min}{ }^{-1}$. All temperatures correspond to the peak maximum.

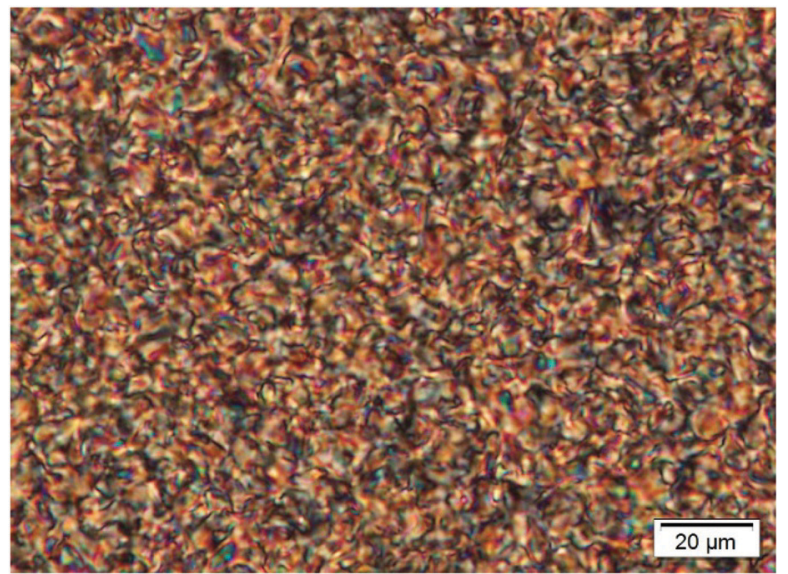

Fig. 3 Photomicrograph of the texture observed by $\mathrm{POM}$ for $\mathrm{T3C}_{4}$ $2 \mathrm{BnOC}_{12}-\mathrm{TPA}_{2} \mathrm{C}_{12}$ at r.t., on cooling from the isotropic liquid at $0.1^{\circ} \mathrm{C} \mathrm{min}^{-1}$.

mesomorphic at room temperature when observed on cooling from the isotropic liquid, their DSC thermograms showed respective cold crystallization processes during the second heating (Fig. S13 and S14, ESI $\dagger$ ), and subsequent melting temperatures higher than those corresponding to the transition between the isotropic liquid and the mesophase on cooling. These findings indicate that their mesophase is thermodynamically unstable and both are monotropic liquid crystals.

The structural features of the mesophases were studied by $\mathrm{X}$-ray diffraction at room temperature on samples cooled from the isotropic liquid. The diffractograms of the three supramolecular complexes $\mathbf{T 3 C}_{\mathbf{4}}-\mathbf{2 B n O C}_{\mathbf{1 2}}-\mathbf{T P A}_{\mathbf{2}} \mathbf{C}_{\mathbf{1 2}}, \mathbf{T 3 C}_{\mathbf{4}}-\mathbf{2 B n O C}_{\mathbf{1 2}} \mathbf{B}^{-}$ TPA4C $_{12}$ and T3C $_{4}-$ - BnOC $_{12}$-TPA6C 12 (Fig. 4 and Fig. S15, ESI $\dagger$ ) contain several reflections in the low angle region, at distances consistent with the relationship $d, d / \sqrt{ } 3, d / \sqrt{ } 4$, which is characteristic of hexagonal columnar mesophases, and corresponding to reflections (100), (110) and (200) of the hexagonal network, respectively (Table S3, ESI $\dagger$ ). The high-angle region contains a diffuse halo that is characteristic of the liquid crystal state, thus confirming that these supramolecular complexes can maintain the mesophase at room temperature, at least during the time of the XRD experiments. The number of complex molecules per unit cell $(Z)$ was estimated from the data obtained by XRD experiments. Since a clear outer reflection indicative of a periodic stacking distance along the columns was not observed for any of the complexes, a stacking distance $c=3.4 \AA$ was considered as observed in related complexes between $\mathbf{T} 3 \mathbf{C}_{4}$ and benzoic acids. ${ }^{39 d}$ Assuming a density value of $1 \mathrm{~g} \mathrm{~cm}^{-3}, Z=1$ was deduced for the three complexes. The columnar arrangement is formed then by the stacking of one supramolecular complex. In such a way the columns have different coaxial circular regions (Fig. 4b), with the $\mathbf{T} 3 \mathbf{C}_{\mathbf{4}}$ moiety occupying the centre of the column (blue area), the dendritic part in the middle (grey area) and the TPA units radially distributed at the periphery (red area).

\section{Electrochemical properties}

In order to determine the redox potentials and the HOMO and LUMO levels of the complexes, their electrochemical properties 
a)

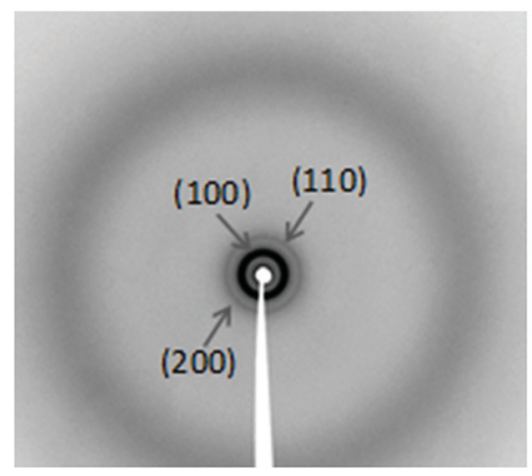

b)

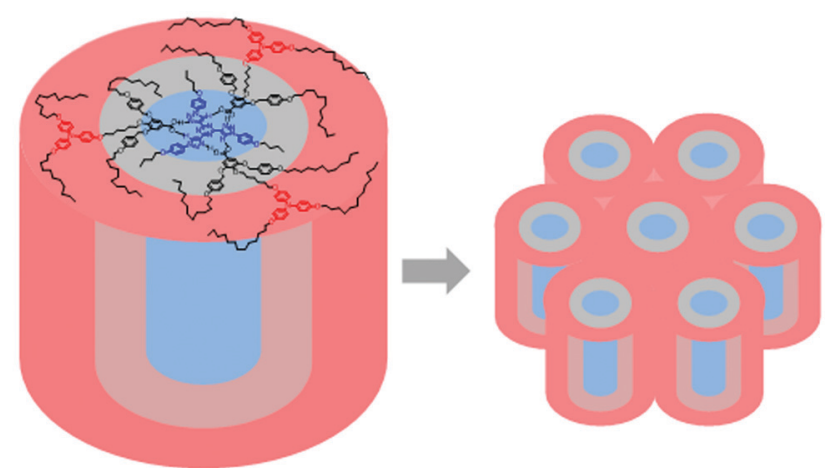

Fig. 4 (a) X-ray diffractogram taken at r.t. for the supramolecular complex $\mathrm{T}_{3} \mathrm{C}_{4}-2 \mathrm{BnOC}_{12}-\mathrm{TPA}_{2} \mathrm{C}_{12}$ cooled from the isotropic liquid: (b) model for the organization of the supramolecular complexes in the $\mathrm{Col}_{h}$ mesophase.

were studied by cyclic voltamperommetry in solution and in film.

The voltamperograms of the complexes in dichloromethane solution showed a reversible oxidation wave at around 0.46$0.57 \mathrm{~V}$ (relative to the $\mathrm{Ag} / \mathrm{AgCl}$ electrode), which corresponds to the oxidation of the triphenylamine units to the radical cation (Table 2).$^{49}$ The presence of the electron-donating alkoxy chains in the triphenylamine units causes a decrease in the oxidation potential with respect to derivatives without such substituents $(1.25 \mathrm{~V}) .{ }^{49}$ This allows a HOMO value of around $-4.9 \mathrm{eV}$ to be calculated. The TPA radical cation can be oxidized to a dication and undergo subsequent chemical reactions. ${ }^{49-51}$ As a consequence, additional oxidation waves were observed for all complexes at more positive potentials on measuring larger potential windows (Fig. S16, ESI $\dagger$ ). In addition, due to the presence of $\mathbf{T 3 C}_{4}$, which is an electron acceptor, a reduction wave was also observed in the voltamperograms of the complexes. This signal corresponds to reduction potentials between $-1.66 \mathrm{~V}$ and $-1.68 \mathrm{~V}$ and allows a similar LUMO value of $-2.7 \mathrm{eV}$ to be calculated for all complexes. ${ }^{41}$

Given the stability of the hexagonal columnar mesophase at room temperature, the electrochemical properties of the complex T3C $_{4}$-2BnOC 12 -TPA2C12 were also studied in a film deposited onto the disk electrode and immersed in a nonsolvent containing the electrolyte (acetonitrile). In this case the voltamperogram (Table 2 and Fig. S17, ESI $\dagger$ ) shows an oxidation wave with maximum at $0.78 \mathrm{~V}$ and a reduction wave at $-1.67 \mathrm{~V}$. The voltamperograms of the precursory acids under the same conditions (solution or film) only showed oxidation processes at similar potentials to the complexes (Tables S4, S5 and Fig. S18, S19, ESI $\dagger$ ). This indicates independent behaviour of the TPA and $\mathbf{T}_{3} \mathbf{C}_{4}$ units.

Cyclic voltammetry measurements on the supramolecular complexes are consistent with the electron-donor character of the TPA units and the electron-acceptor character of $\mathbf{T 3 C}_{4}$. In addition, the HOMO and LUMO values calculated from these measurements may be suitable to give rise to ambipolar transport properties in the columnar organization of these complexes.

\section{Charge carrier mobility measurements}

Given the HOMO energy level of $\mathbf{T 3 C}_{\mathbf{4}}-\mathbf{2 B n O C}_{\mathbf{1 2}}$-TPA2 $\mathbf{C}_{\mathbf{1 2}}$, $E_{\mathrm{Hомо}}=-5.15 \mathrm{eV}$, this compound is ideally suited for an evaluation of its hole transport properties via the Space Charge Limited Current (SCLC) method, using Au as an injecting electrode with ohmic contact (Fig. S20, ESI†). Samples were prepared as described in the ESI $\dagger$ and a description of the measurements is also included (Fig. S21, ESI $\dagger$ ).

The SCLC method probes charge drift across the whole thickness of the samples, in our case typically of the order of $10 \mu \mathrm{m}$. As a consequence, in anisotropic media the observed mobility value is highly dependent on the size of the ordered domains and on their orientation with respect to the direction of measurement. As assessed by POM (Fig. S22, ESI $\dagger$ ), the director distribution was never homogeneous in the samples of $\mathbf{T}_{3} \mathbf{C}_{4}-\mathbf{B B n O C}_{\mathbf{1 2}}-\mathbf{T P A 2}_{\mathbf{1 2}}$, not even on a submillimeter-scale. Nonetheless, a mobility in the range $10^{-9}-10^{-8} \mathrm{~cm}^{2} \mathrm{~V}^{-1} \mathrm{~s}^{-1}$, which is typical of amorphous phases, was measured in numerous different areas of samples obtained after slow cooling from the melt.

The situation changed when thermal treatments were carried out as described in the ESI. $\dagger$ Even though the POM analysis did not show any marked variation in the homogeneity of the director distribution, it was possible to measure much higher

Table 2 Electrochemical data for the supramolecular complexes T3C $-2 \mathrm{BnOC}_{12}-\mathrm{TPA}_{2} \mathrm{C}_{12}, \mathrm{T3C}_{4}-2 \mathrm{BnOC}_{12}-\mathrm{TPA}_{42}$ and T3C $4-2 \mathrm{BnOC}_{12}-\mathrm{TPA}_{12} \mathrm{C}_{12}$

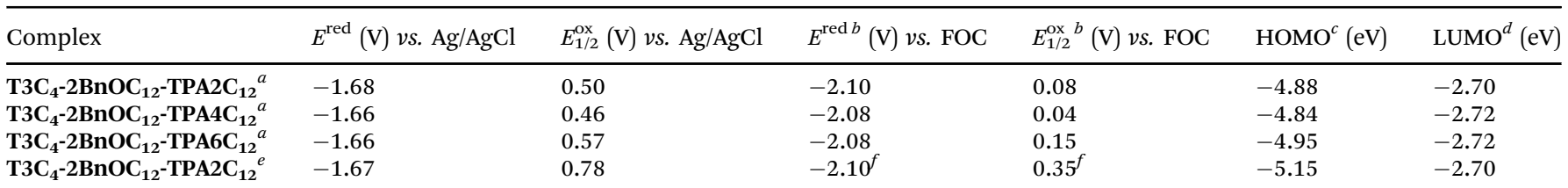

${ }^{a}$ In dichloromethane solution. ${ }^{b} E_{1 / 2}=0.42 \mathrm{~V} v s . \mathrm{Ag} / \mathrm{AgCl} .{ }^{c} E_{\mathrm{HOMO}}=-e\left[E_{1 / 2}^{\mathrm{ox}} v s . \mathrm{FOC}+4.8 \mathrm{~V}\right] .{ }^{d} E_{\mathrm{LUMO}}=-e\left[E^{\mathrm{red}} v s . \mathrm{FOC}+4.8 \mathrm{~V}\right] .{ }^{e}$ Thin film in acetonitrile. ${ }^{f} E_{1 / 2}=0.43 \mathrm{~V} v s . \mathrm{Ag} / \mathrm{AgCl}$. 


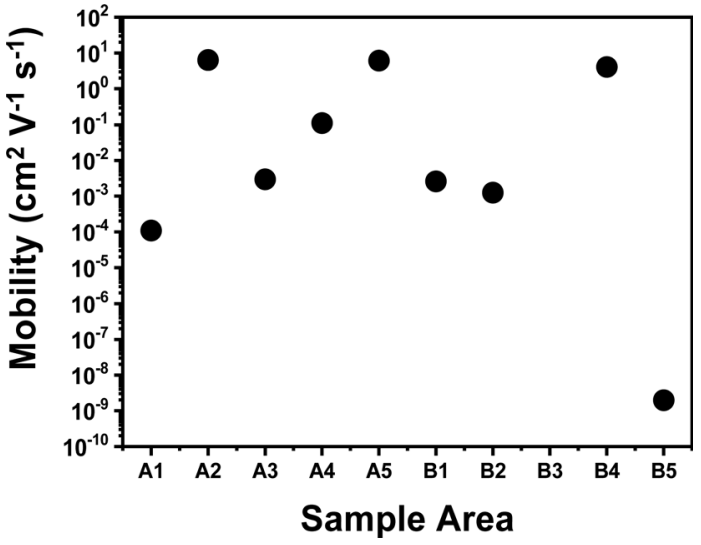

Fig. 5 A typical example of hole mobilities measured in different areas (labelled A1, A2, etc.) of the same sample of $\mathbf{T}^{3} \mathrm{C}_{4}-\mathbf{2} \mathbf{B n O C}_{12}-\mathrm{TPA}_{2} \mathrm{C}_{12}$ after thermal treatment

mobility values, albeit ranging within 4-5 orders of magnitude between $10^{-4}$ and more than $1 \mathrm{~cm}^{2} \mathrm{~V}^{-1} \mathrm{~s}^{-1}$. The results of a typical set of measurements in different areas of the same sample are shown in Fig. 5. We attribute the width of the range of the measured mobility values to different orientational environments. The evident alignment of the highest measured values of mobility towards a limiting maximum is suggestive of a disorder limited mobility: in this view, the limiting value could be considered as the hole mobility along the columns when the orientational disorder and the effect of traps at grain boundaries is minimized. Considering the highest values measured on different samples, which seem to lie nicely within a limited range, we obtain a mobility $\mu \approx 5 \mathrm{~cm}^{2} \mathrm{~V}^{-1} \mathrm{~s}^{-1}$. These SCLC results indicate that the order of magnitude of hole mobility when TPA units are embedded within columnar phases can be much higher than in amorphous TPA phases, if orientational disorder is minimized.

In order to evaluate electron mobility, samples were prepared in which a $\sim \mathbf{5}-10 \mu \mathrm{m}$ thick layer of $\mathbf{T}_{\mathbf{4}} \mathbf{C}_{\mathbf{4}}-\mathbf{2 B n O C}_{\mathbf{1 2}}$-TPA2C $\mathbf{C}_{\mathbf{1 2}}$ was sandwiched between two ITO electrodes covered with a thin layer of $\mathrm{ZnO}$. However, regardless of the type of thermal treatment carried out, currents were always low, although SCLC regimes were often obtained. The resulting electron mobility, of the order of $10^{-9}-10^{-8} \mathrm{~cm}^{2} \mathrm{~V}^{-1} \mathrm{~s}^{-1}$, should then be taken as lower limit, probably a consequence of the poor injection from the $\mathrm{ZnO}$ layer.

\section{Theoretical calculations}

The star-shaped $\mathbf{T} 3 \mathbf{C}_{\mathbf{4}}$ core was theoretically studied in a previous work at the B3LYP-D3/6-31G** level of theory and the $C_{3}$ conformation was computed to be more stable than the asymmetric one. ${ }^{39 e}$ In addition, the $\mathrm{H}$-bond interaction between the core and benzoic acid was scrutinized in order to draw conclusions about the most stable host-guest supramolecular structure. ${ }^{39 e}$ In this work, we considered these previous results to calculate the structure and properties of the supramolecular complex between $\mathbf{T} 3 \mathbf{C}_{\mathbf{4}}$ and the TPA-derived benzoic acid. Since the hydrogen bonds established between the $\mathbf{T} 3 \mathbf{C}_{4}$ core and three benzoic acid molecules play an important role in the stability of the complex, and hence in the selfassembly of the columnar mesophase, it was interesting to explore theoretically the structure and stability of the complex geometry. Taking into account the larger size of the complex studied in this work, a simplified model complex, T3C1-2BnOC $\mathbf{1}_{\mathbf{1}}-\mathbf{T P A}_{\mathbf{2}} \mathbf{C}_{\mathbf{1}}$, which is an analog of $\mathbf{T}_{3} \mathbf{C}_{\mathbf{4}}-\mathbf{2} \mathbf{B n O C}_{\mathbf{1 2}}$-TPA2 $_{\mathbf{1 2}}$ but with methoxy groups in the core and the TPA unit, was fully optimized at the $\omega \mathrm{B} 97 \mathrm{XD} /$ $6-31 G^{* *}$ level of theory without symmetry constraints. This longrange functional includes dispersion corrections and has proven to be suitable in similar studies in which $\pi-\pi$ interactions and hydrogen bonds are present. $^{52}$

The optimized structure of the $\mathbf{T}_{\mathbf{1}} \mathbf{2}-\mathbf{2} \mathbf{B n O C} \mathbf{1}-\mathbf{T P A}_{\mathbf{2}} \mathbf{C}_{\mathbf{1}}$ complex is shown in Fig. 6. The directionality of the H-bonds is a key parameter to describe the strength of these noncovalent interactions, which have a high impact on the selfassembly of liquid crystals and their structure-property relationships. ${ }^{53}$ According to Jeffrey's criteria, ${ }^{54}$ our theoretical calculations predict that the hydrogen bonds in $\mathbf{T} 3 \mathbf{C}_{\mathbf{1}}-\mathbf{2} \mathbf{B n O C} \mathbf{C}_{\mathbf{1}}$ TPA2C $_{1}$ could be classified as moderate. A zoomed view of the T3C $_{\mathbf{1}}$-2BnOC -TPA2C $_{\mathbf{1}}$ scaffold is shown in Fig. 6 and it can be seen that each triazole ring is bonded to a benzoic acid moiety via two nonlinear hydrogen bonds, i.e., less than 180 degrees, with angles for the $\mathrm{C}-\mathrm{H} \cdots \mathrm{O}$ contacts that are more directional than those for $\mathrm{O}-\mathrm{H} \cdots \mathrm{N}$.

The mean values for the $\mathrm{C}-\mathrm{H} \cdots \mathrm{O}$ and $\mathrm{O}-\mathrm{H} \cdots \mathrm{N}$ bond angles are $169.4^{\circ}$ and $153^{\circ}$, respectively, while the $\mathrm{H} \cdots \mathrm{O}$ interaction is predicted to be longer than $\mathrm{H} \cdots \mathrm{N}$, with values of $1.959 \AA$ and $1.870 \AA$, respectively. These results are consistent with distances calculated at the B3LYP-D3/6-31G** level for a complex between $\mathbf{T 3 C}_{4}$ and a 3,4,5-(4-alkoxybenzyloxy)benzoic acid (2.033 and $1.801 \AA$, respectively). ${ }^{39 e}$

Several relevant dihedral angles for the $\mathbf{T} 3 \mathbf{C}_{\mathbf{4}}$ core are also included in Fig. 6. The triazole ring is almost coplanar with triazine $\left(<6^{\circ}\right)$ while it is significantly twisted with respect to the peripheral benzene groups, with dihedral angles of around $\sim 31^{\circ}$. This structure is consistent with our previous theoretical studies on the $\mathbf{T} 3 \mathbf{C}_{\mathbf{4}}$ molecule - either alone or complexed with benzoic acids ${ }^{39 e}$ - performed at the B3LYP-D3/6-31G** level of theory. In addition, the dihedral angles for two phenyl rings of the triphenylamine moiety are also included in Fig. 6, with angles in the range $38-45^{\circ}$, in agreement with the twisted structure of TPA. ${ }^{55}$

The HOMO and LUMO molecular orbitals for the optimized structure are shown in Fig. 7, together with their corresponding energy levels. It is clear that LUMO and LUMO+1 are degenerate and the same applies to HOMO, HOMO-1 and HOMO-2. The HOMO and LUMO wavefunctions are highly localized on the three electron-donor triphenylamine units and the electronacceptor tris(triazolyl)triazine core, respectively, although the propeller shape of these units could be to the detriment of the hole and electron charge transport through the columnar mesophase. As a result of the different physical localization of the HOMO and LUMO, holes and electrons could flow independently through different charge transport molecular wires along the columnar mesophase.

To gain a more comprehensive understanding of the semiconductor properties of the $\mathbf{T} 3 \mathbf{C}_{\mathbf{1}}-\mathbf{2} \mathbf{B n O C} \mathbf{C}_{\mathbf{1}}-\mathbf{T P A} \mathbf{2} \mathbf{C}_{\mathbf{1}}$ complex, typical electronic properties such as electron affinity, ionization potential, 

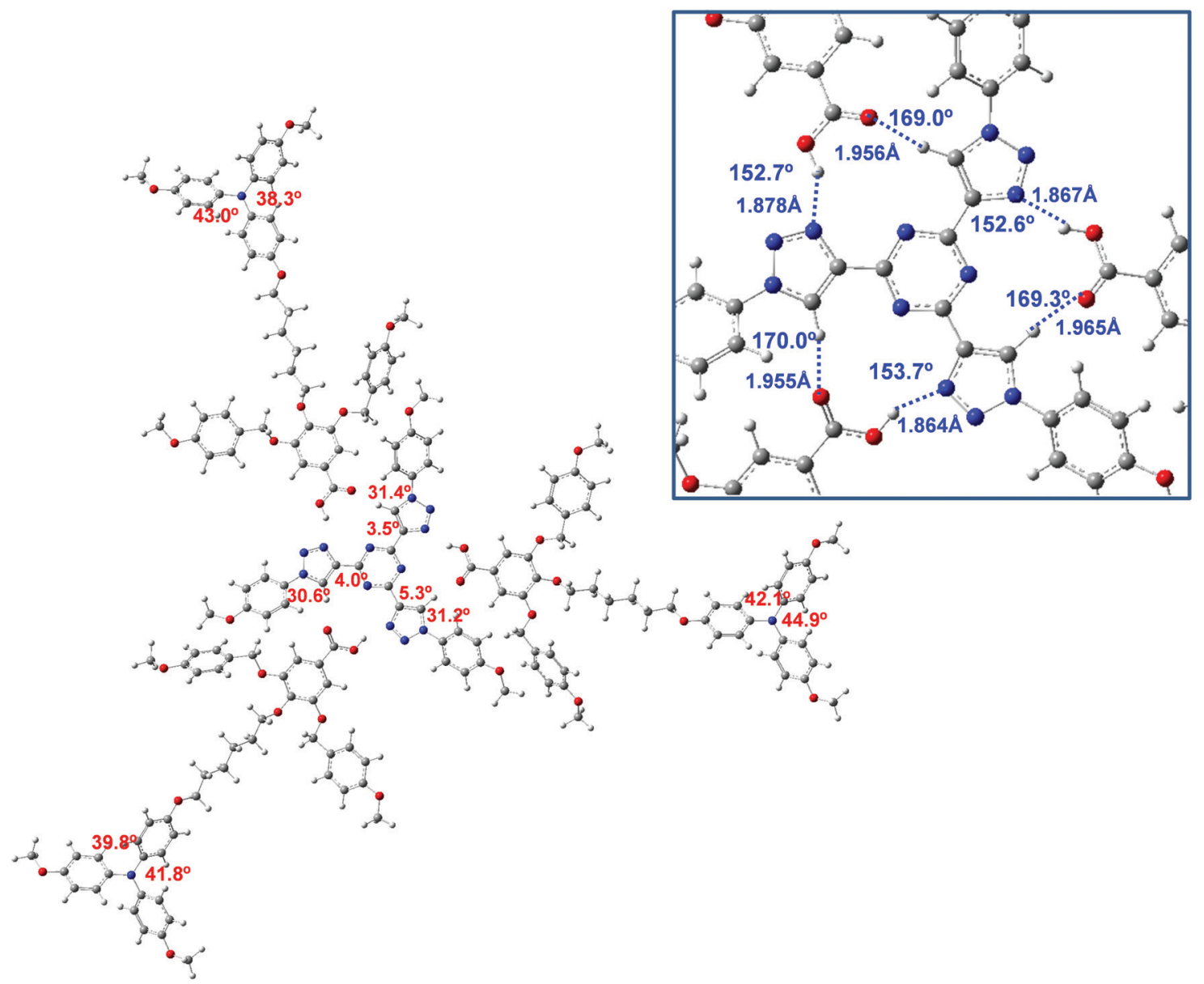

Fig. 6 Optimized $\mathrm{T3C}_{1}-\mathbf{2} \mathrm{BnOC}_{1}-\mathrm{TPA}_{2} \mathrm{C}_{1}$ complex at the $\omega \mathrm{B} 97 \mathrm{XD} / 6-31 \mathrm{G}^{\star \star}$ level of theory.

reorganization energy and transfer integral were calculated to estimate the efficiency of charge injection and charge transport. The calculations were also performed on the $\mathbf{T} 3 \mathbf{C}_{\mathbf{1}}$ core and the TPA3C $_{1}$ as references (see Fig. S23, ESI $\dagger$ ). Inspection of the calculated properties shown in Table 3 indicates that both moieties determine to a large extent the electronic properties of the final complex.

TPA has fascinated researchers as a p-type semiconductor that has many applications in organic electronics despite the fact that its non-planar structure hinders the molecular orbital overlap for charge transport. Our theoretical results for TPA are in agreement with those previously calculated by Lin et al. ${ }^{55}$ using B3LYP/6-31G* and with those by Cias et al. on a series of para-substituted triphenylamines at the B3LYP/TZVP level of theory, ${ }^{56}$ although the results are not rigorously comparable due to the different functional and basis set used. In the case of the tris(triazolyl)triazine core, it is worth noting that this is the first theoretical study concerning its semiconductor-related properties.

The reorganization energy calculated for the $\mathbf{T} 3 \mathbf{C}_{\mathbf{1}}-\mathbf{2} \mathbf{B n O C} \mathbf{C}_{\mathbf{1}}$ TPA2C $_{1}$ complex shows that hole transport would be more favoured than electron transport, with $\lambda_{+}$being almost half $(0.310 \mathrm{eV})$ of $\lambda_{-}(0.688 \mathrm{eV})$. The relative value $\lambda_{-} / \lambda_{+} \sim 2$ for
T3C $_{\mathbf{1}}-$ - BnOC $_{\mathbf{1}}-$ TPA2C $_{\mathbf{1}}$ is close to that calculated by Lin et al. ${ }^{55}$ for the TPA unit using B3LYP/6-31G*. However, higher values for both $\lambda_{-}$and $\lambda_{+}$were obtained for the $\mathbf{T} 3 \mathbf{C}_{\mathbf{1}}$ core and $\lambda_{-}<\lambda_{+}$ is consistent with its electron acceptor character.

The ionization potential and electron affinity were also calculated for $\mathbf{T} 3 \mathbf{C}_{\mathbf{1}}-\mathbf{2} \mathbf{B n O C} \mathbf{C}_{\mathbf{1}}-\mathbf{T P A} \mathbf{2} \mathbf{C}_{\mathbf{1}}$ (see Table 3) and the results show that hole injection would be favored over electron injection. Thus, the predicted value for the ionization potential is in the range of typical p-type semiconductors such as TPA, ${ }^{56}$ while the electron affinity calculated for the $\mathbf{T} 3 \mathbf{C}_{\mathbf{1}}-\mathbf{2} \mathbf{B n} \mathbf{O} \mathbf{C}_{\mathbf{1}}$ TPA2C $\mathbf{1}_{1}$ complex and the $\mathbf{T 3 C}_{\mathbf{1}}$ core is far from the limit of $3 \mathrm{eV}$ for typical n-type semiconductors. ${ }^{57}$

In order to estimate the molecular orbital overlap and charge transfer integral between two $\mathbf{T} 3 \mathbf{C}_{\mathbf{1}}-\mathbf{2} \mathbf{B n O C}_{\mathbf{1}}-\mathbf{T P A}_{\mathbf{2}} \mathbf{C}_{\mathbf{1}}$ units, a full geometry optimization was performed on a stacked dimer of the complex. The dimer was built using the optimized molecular geometry of the isolated complex (Fig. 6). The initial stacking distance was $3.5 \AA$, based on a typical interdisk distance in columnar liquid crystals. ${ }^{2}$ One disk was slightly rotated relative the other $\left(10^{\circ}\right)$ to prevent steric repulsion. The optimized structure of the dimer is represented in Fig. 8a and it can be seen that the $\mathbf{T} 3 \mathbf{C}_{\mathbf{1}}$ cores are rotated by around $15^{\circ}$ with respect to each other, with an interdisk distance between the 

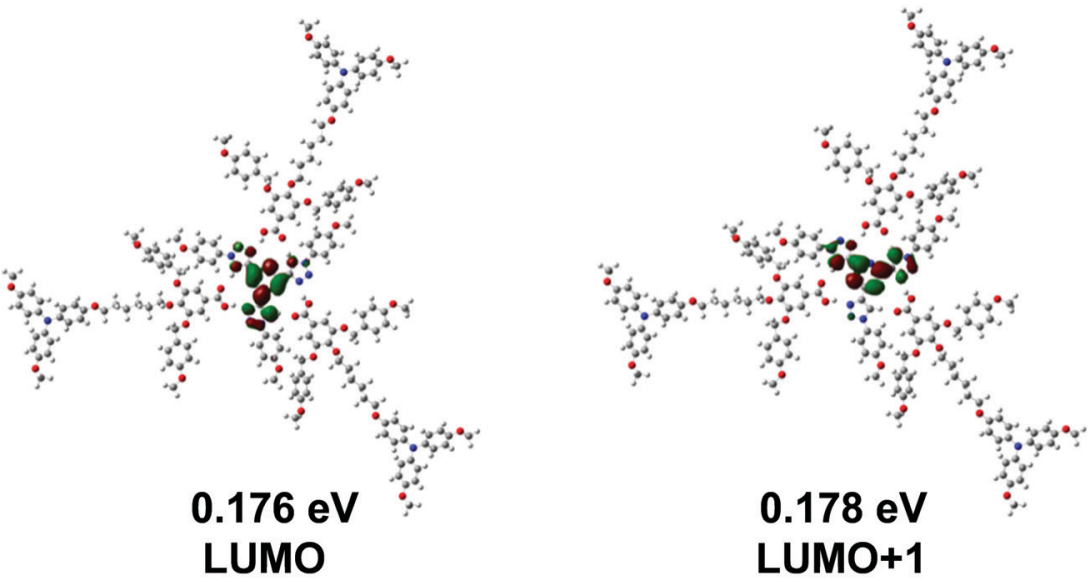

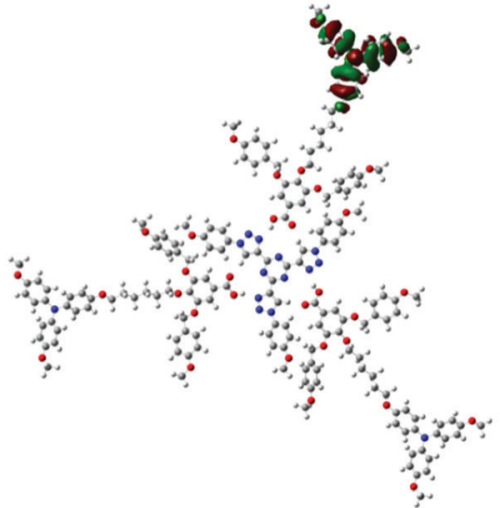

$-6.241 \mathrm{eV}$ HOMO

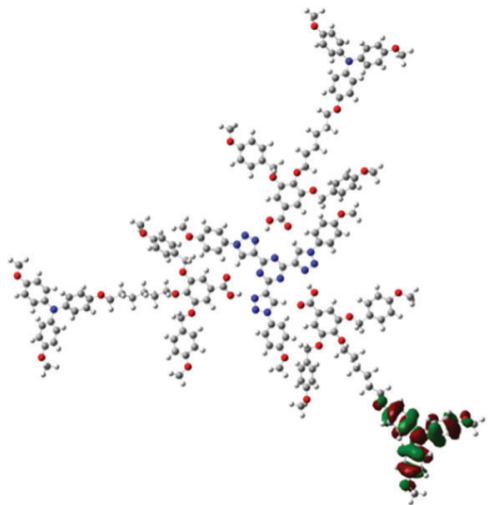

$-6.252 \mathrm{eV}$ HOMO-1

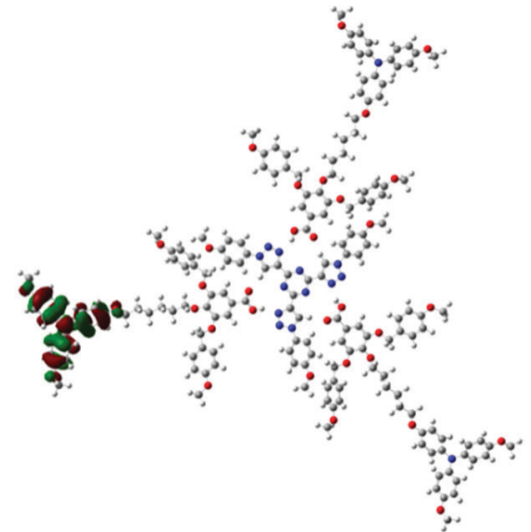

\section{$-6.253 \mathrm{eV}$ HOMO-2}

Fig. 7 Shapes of the frontier molecular orbitals for $\mathrm{T}^{3} \mathrm{C}_{1}-2 \mathrm{BnOC}_{1}-\mathrm{TPA}_{2} \mathrm{C}_{1}$ calculated at the $\omega \mathrm{B} 97 \mathrm{XD} / 6-31 \mathrm{G}^{* *}$ level of theory in the gas phase (isocontour plots (0.02 a.u.)).

Table 3 Hole $\left(\lambda_{+}\right)$and electron $\left(\lambda_{-}\right)$reorganization energies, Adiabatic Ionization Potential (AIP) and Electron Affinities (in eV) for T3C , $_{1}$ TPA3C and T3C1-2BnOC $_{1}-$ TPA2 $_{1}$ complex calculated at the $\omega \mathrm{B} 97 \mathrm{XD} / 6-31 \mathrm{G}^{* *}$ level of theory in the gas phase

\begin{tabular}{llllr}
\hline Compound & $\lambda_{+}$ & $\lambda_{-}$ & AIP & \multicolumn{1}{c}{ AEA } \\
\hline T3C $_{\mathbf{1}}$ & 0.775 & 0.519 & 7.533 & 0.312 \\
TPA3C $_{\mathbf{1}}$ & 0.297 & 0.397 & 5.875 & -1.388 \\
T3C1-2BnOC $_{\mathbf{1}}$-TPA2C $_{\mathbf{1}}$ & 0.310 & 0.688 & 5.698 & 0.720
\end{tabular}

two centers of the triazine rings of around $3.4 \AA$, which is in agreement with our previous results. ${ }^{39 d, e}$ One important consequence of such a limited rotation angle is that TPA units of adjacent complexes in the same column end up close enough in space to interact with each other.

An expanded view of the two $\mathbf{T} 3 \mathbf{C}_{\mathbf{1}}$ cores in the optimized dimer is also presented in Fig. 8 along with bond distances and angles for the hydrogen bonds, which are similar to those obtained for the optimized isolated complex. An enlarged view of the stacked TPA regions is shown in Fig. 9 including the distances between the centers of phenyl rings (in red) and also some distances between carbon atoms (in black). It could be expected that the most advantageous arrangement for molecular orbital overlap would be in the a region in which the two TPA

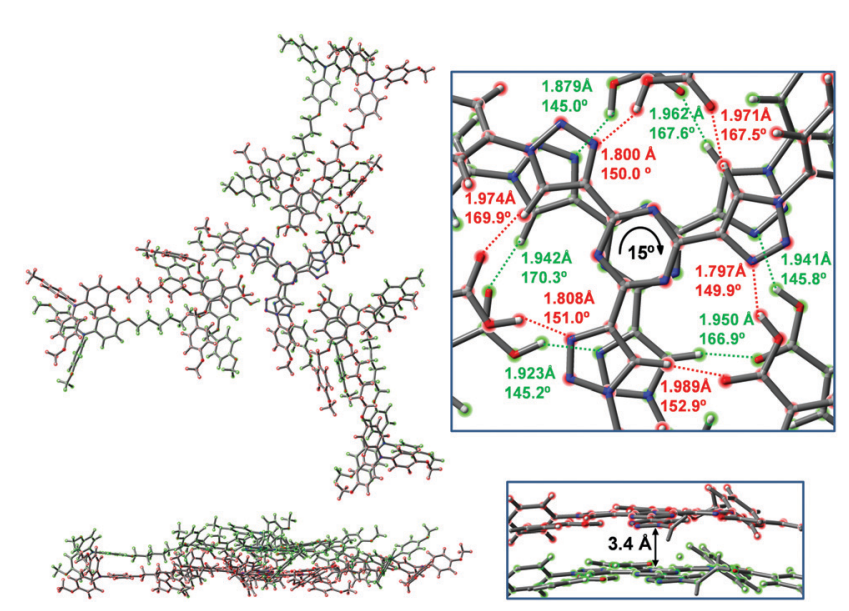

Fig. 8 Top and side views of the optimized dimer of the $\mathrm{T}_{3} \mathrm{C}_{\mathbf{1}}-\mathbf{2} \mathrm{BnOC}_{\mathbf{1}}$ TPA2C $_{1}$ complex at the $\omega B$ 97XD/6-31G** level of theory. Two different colors are used to highlight the two complexes that form the dimer. The expanded view shows bond distances and angles for the hydrogen bonding interactions. 

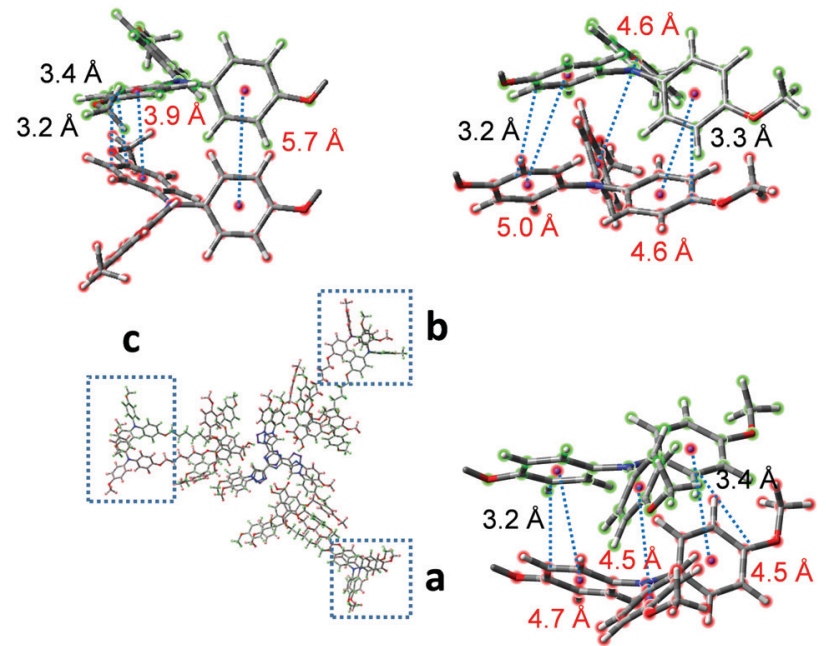

Fig. 9 Enlarged view of the TPA regions showing distances between the centers of phenyl rings (in red) and some distances between carbon atoms (in black).

units stack one on top of the other although large distances were predicted (4.5-4.7 $\mathrm{\AA}$ ) which would be in detriment of the charge transport. A more favored situation is found in $\mathrm{c}$ where two phenyl rings could become closer (3.9 A) being a bit away from the typical $\pi$-stacking distance $(3.5 \AA)$. However, shorter distances were predicted between some carbon atoms (3.2-3.4 $⿱$ ) in favor of the molecular orbital overlap.

The charge transfer integral was estimated at the $\omega \mathrm{B} 97 \mathrm{XD} /$ $6-31 G^{* *}$ level of theory for the stacked dimer with values of $0.029 \mathrm{eV}\left(t_{+}\right)$and $0.110 \mathrm{eV}(t-)$ obtained for holes and electrons, respectively. According to the Marcus equation, the calculated hopping rate constant was $k_{+}=1.24 \times 10^{12} \mathrm{~s}^{-1}$ and $k_{-}=3.02 \times$ $10^{11} \mathrm{~s}^{-1}$, thus suggesting better hole transport than electron transport $\left(k_{+}>k_{-}\right)$. As previously stated, the calculated AEA is far from those of typical n-type semiconductors, and this is related to easy electron injection. ${ }^{58,59}$ Besides, the interface between the injection layer and the semiconductor is usually treated as a Mott-Schottky barrier, where the barrier height is given by the difference between the metal work function $(\Phi)$ and the (gas) semiconductor LUMO level. ${ }^{60}$ In order to obtain a good ohmic contact between semiconductor materials and electrodes, potential barriers lower than $0.2-0.3 \mathrm{eV}$ are generally expected. ${ }^{60,61}$

Taking into account the fact that the metal work function of $\mathrm{ZnO}$ is $4.3 \mathrm{eV}$, the predicted barrier height should be $4.3-$ $0.176=4.1 \mathrm{eV}$. Thus, our calculations support the hypotheses that the difficulty in obtaining electron mobility values may not be attributable to the intrinsic properties of the material, but probably to poor charge injection.

\section{Conclusions}

It has been demonstrated in a new precedent that a known hole transport unit, TPA, can be organized in LC phases with semiconducting properties using a supramolecular approach.
The preparation of hydrogen bonded 1:3 complexes of a star-shaped triazine acceptor core and three TPA donor peripheral units gave rise to columnar LC phases. The columnar phase shows high hole mobility after thermal treatment, with very high mobility values, up to $\mu \approx 5 \mathrm{~cm}^{2} \mathrm{~V}^{-1} \mathrm{~s}^{-1}$, that can be considered as a mobility along the columns when the effects of static defects and grain boundaries are minimized.

Generally, charge transport in columnar LC phases can be traced back to the stacking of the central part of the columns, while the external section, with a higher number of conformational degrees of freedom, mainly plays a space filling role and it is referred to as the insulating area. However, in the present case, the measured hole mobility can be ascribed to the TPA units present in the external, more flexible section of the columns. Here the phase structure acts as a scaffold used to position TPA units close enough to each other to promote charge transfer while at the same time preventing crystallization. The local degree of order of the columnar phase, related to the organization of the central cores, is thus of secondary importance for charge mobility, while the length scale of the long range orientational uniformity, i.e. the average size of the orientational domains, plays a more dominant role.

DFT theoretical investigations on such supramolecular systems were undertaken despite the large size of the complex. An optimized structure was identified for which molecular orbitals could be studied. In addition, this is the first theoretical study on 2,4,6-tris(triazolyl)-1,3,5-triazine semiconductor properties and also unprecedented on the theoretical study of triphenylaminecontaining supramolecules. As a result of the different physical localization of the HOMO and LUMO, holes and electrons could flow independently along the columns. The calculations for a stacked dimer suggest better hole transport than electron transport, but this is not attributable to the intrinsic properties of the material and is probably due to poor charge injection, as also evidenced by experimental results.

This work is one of the few examples that show a combined experimental and theoretical approach for the design and evaluation of complex supramolecular systems for organic semiconductors. Although further work aimed at modeling through molecular dynamics calculations could shed light on the details of the stacking geometry of TPA groups, including the effects of intercolumnar interactions, and thus provide further insight regarding the reasons of the improved mobility, the evidence presented here already indicates that a certain degree of order, like the one typical of a columnar organization, contributes to enhance hole mobility in TPA based compounds.

\section{Conflicts of interest}

There are no conflicts to declare.

\section{Acknowledgements}

This work was financially supported by the MICIU-FEDER funds (project PGC2018-093761-B-C31), the Gobierno de Aragón-FSE 
(E47_20R and B. F. grant B084/13), the Consejería de Economía y Conocimiento, Junta de Andalucía (FQM-337), and the Universidad de Jaén (Acción 1). A. G. thanks support from the ELIOTROPO project (PON03PE_00092_2). R. T. was supported by the MERAVIGLIE project (CUP J28C17000080006). The authors would like to thank the Centro de Servicios de Informática y Redes de Comunicaciones (CSIRC), Universidad de Granada, for providing the computing time and the Servicios Generales de Apoyo a la Investigación-SAI and CEQMA, Universidad de Zaragoza-CSIC. We acknowledge support of the publication fee by the CSIC Open Access Publication Support Initiative through its Unit of Information Resources for Research (URICI).

\section{References}

1 T. Kato, J. Uchida, T. Ichikawa and T. Sakamoto, Angew. Chem., Int. Ed., 2018, 57, 4355-4371.

2 T. Wöhrle, I. Wurzbach, J. Kirres, A. Kostidou, N. Kapernaum, J. Litterscheidt, J. C. Haenle, P. Staffeld, A. Baro, F. Giesselmann and S. Laschat, Chem. Rev., 2016, 116, 1139-1241.

3 T. Kato, M. Yoshio, T. Ichikawa, B. Soberats, H. Ohno and M. Funahashi, Nat. Rev. Mater., 2017, 2, 17001.

4 Y. Shirota and H. Kageyama, Chem. Rev., 2007, 107, 953-1010.

5 J. Y. Wang, K. Liu, L. C. Ma and X. W. Zhan, Chem. Rev., 2016, 116, 14675-14725.

6 P. Agarwala and D. Kabra, J. Mater. Chem. A, 2017, 5, 1348-1373.

7 U. Bach, K. De Cloedt, H. Spreitzer and M. Gratzel, Adv. Mater., 2000, 12, 1060-1063.

8 H. Ohishi, M. Tanaka, H. Kageyama and Y. Shirota, Chem. Lett., 2004, 33, 1266-1267.

9 H. H. Fong, A. Papadimitratos and G. G. Malliaras, Appl. Phys. Lett., 2006, 89, 172116.

10 A. Cravino, S. Roquet, O. Aleveque, P. Leriche, P. Frere and J. Roncali, Chem. Mater., 2006, 18, 2584-2590.

11 Y. B. Song, C. A. Di, X. D. Yang, S. P. Li, W. Xu, Y. Q. Liu, L. M. Yang, Z. G. Shuai, D. Q. Zhang and D. B. Zhu, J. Am. Chem. Soc., 2006, 128, 15940-15941.

12 T. Malinauskas, M. Daskeviciene, G. Bubniene, I. Petrikyte, S. Raisys, K. Kazlauskas, V. Gaidelis, V. Jankauskas, R. Maldzius, S. Jursenas and V. Getautis, Chem. - Eur. J., 2013, 19, 15044-15056.

13 R. J. Li, H. X. Li, Y. B. Song, Q. X. Tang, Y. L. Liu, W. Xu, W. P. Hu and D. B. Zhu, Adv. Mater., 2009, 21, 1605-1608.

14 W. M. Zhang, J. Smith, R. Hamilton, M. Heeney, J. Kirkpatrick, K. Song, S. E. Watkins, T. Anthopoulos and I. McCulloch, J. Am. Chem. Soc., 2009, 131, 10814-10815.

15 Y. Shirota, J. Mater. Chem., 2005, 15, 75-93.

16 S. Allard, M. Forster, B. Souharce, H. Thiem and U. Scherf, Angew. Chem., Int. Ed., 2008, 47, 4070-4098.

17 Z. Ning and H. Tian, Chem. Commun., 2009, 5483-5495.

18 C. Rodríguez-Seco, L. Cabau, A. Vidal-Ferran and E. Palomares, Acc. Chem. Res., 2018, 51, 869-880.
19 A. N. Sobolev, V. K. Belsky, I. P. Romm, N. Y. Chernikova and E. N. Guryanova, Acta Crystallogr., Sect. C: Cryst. Struct. Commun., 1985, 41, 967-971.

20 M. Malagoli and J. L. Bredas, Chem. Phys. Lett., 2000, 327, 13-17.

21 P. Strohriegl and J. V. Grazulevicius, Adv. Mater., 2002, 14, 1439-1452.

22 E. Moulin, J. J. Armao and N. Giuseppone, Acc. Chem. Res., 2019, 52, 975-983.

23 V. Faramarzi, F. Niess, E. Moulin, M. Maaloum, J.-F. Dayen, J.-B. Beaufrand, S. Zanettini, B. Doudin and N. Giuseppone, Nat. Chem., 2012, 4, 485-490.

24 J. Kim, J. Lee, W. Y. Kim, H. Kim, S. Lee, H. C. Lee, Y. S. Lee, M. Seo and S. Y. Kim, Nat. Commun., 2015, 6, 6959.

25 T. Kim, T. Mori, T. Aida and D. Miyajima, Chem. Sci., 2016, 7, 6689-6694.

26 B. Adelizzi, I. A. W. Filot, A. R. A. Palmans and E. W. Meijer, Chem. - Eur. J., 2017, 23, 6103-6110.

27 A. Osypenko, E. Moulin, O. Gavat, G. Fuks, M. Maaloum, M. A. J. Koenis, W. J. Buma and N. Giuseppone, Chem. - Eur. J., 2019, 25, 13008-13016.

28 E. Moulin, F. Niess, M. Maaloum, E. Buhler, I. Nyrkova and N. Giuseppone, Angew. Chem., Int. Ed., 2010, 49, 6974-6978.

29 T. K. Ellis, M. Galerne, J. J. Armao IV, A. Osypenko, D. Martel, M. Maaloum, G. Fuks, O. Gavat, E. Moulin and N. Giuseppone, Angew. Chem., Int. Ed., 2018, 57, 15749-15753.

30 Y. Domoto, E. Busseron, M. Maaloum, E. Moulin and N. Giuseppone, Chem. - Eur. J., 2015, 21, 1938-1948.

31 (a) K. C. Majumdar, N. Pal, P. Debnath and N. V. S. Rao, Tetrahedron Lett., 2007, 48, 6330-6333; (b) K. C. Majumdar, B. Chattopadhyay, P. K. Shyam and N. Pal, Tetrahedron Lett., 2009, 50, 6901-6905.

32 T. D. Choudhury, N. V. S. Rao, R. Tenent, J. Blackburn, B. Gregg and I. I. Smalyukh, J. Phys. Chem. B, 2011, 115, 609-617.

33 Y. J. Wang, H. S. Sheu and C. K. Lai, Tetrahedron, 2007, 63, 1695-1705.

34 D. B. Amabilino, D. K. Smith and J. W. Steed, Chem. Soc. Rev., 2017, 46, 2404-2420.

35 Functional Supramolecular Materials: From Surfaces to MOFs, ed. R. Banerjee, RSC, 2017.

36 Supramolecular Soft Matter: Applications in Materials and Organic Electronics, ed. T. Nakanishi, Wiley, 2011.

37 T. Kato, J. Uchida, T. Ichikawa and B. Soberats, Polym. J., 2017, 50, 149.

38 T. Kato and Y. Kamikawa, Hydrogen-Bonded Systems: Discrete Defined Aggregates by Intermolecular H-Bonding, Amides, Carboxylic Acids, and Heterocycles (Chapter 10), in Handbook of Liquid Crystals, ed. J. W. Goodby, P. J. Collings, T. Kato, C. Tschierske, H. Gleeson, P. Raynes, Wiley-VCH Verlag GmbH \& Co. KGaA, 2nd edn, 2014, vol. 5, p. 513.

39 (a) F. Vera, R. M. Tejedor, P. Romero, J. Barberá, M. B. Ros, J. L. Serrano and T. Sierra, Angew. Chem., Int. Ed., 2007, 46, 1873-1877; (b) F. Vera, J. Barberá, P. Romero, J. L. Serrano, M. B. Ros and T. Sierra, Angew. Chem., Int. Ed., 2010, 49, 
4910-4914; (c) A. A. Vieira, E. Cavero, P. Romero, H. Gallardo, J. L. Serrano and T. Sierra, J. Mater. Chem. C, 2014, 2, 7029-7038; (d) B. Feringán, P. Romero, J. L. Serrano, R. Giménez and T. Sierra, Chem. - Eur. J., 2015, 21, 8859-8866; (e) B. Feringán, J. Cerdá, B. Diosdado, J. Aragó, E. Ortí, R. Giménez and T. Sierra, Chem. - Eur. J., 2020, 26, 15313-15322.

40 B. Feringán, C. L. Folcia, R. Termine, A. Golemme, J. M. Granadino-Roldán, A. Navarro, J. L. Serrano, R. Giménez and T. Sierra, Chem. - Eur. J., 2018, 24, 17459-17463.

41 B. Feringán, P. Romero, J. L. Serrano, C. L. Folcia, J. Etxebarria, J. Ortega, R. Termine, A. Golemme, R. Giménez and T. Sierra, J. Am. Chem. Soc., 2016, 138, 12511-12518.

42 V. C. Percec, H. Ahn, W. D. Cho, A. M. Jamieson, J. Kim, T. Leman, M. Schmidt, M. Gerle, M. Moller, S. A. Prokhorova, S. S. Sheiko, S. Z. D. Cheng, A. Zhang, G. Ungar and D. J. P. Yeardley, J. Am. Chem. Soc., 1998, 120, 8619-8631.

43 H. Oberhofer, K. Reuter and J. Blumberger, Chem. Rev., 2017, 117, 10319-10357.

44 (a) S. M. Said, M. S. Mahmood, M. N. Daud, M. F. M. Sabri and N. A. Sairi, Liq. Cryst., 2016, 43, 2092-2113; (b) Y. Zhang, D. A. Hanifi, M. P. Fernández-Liencres, L. M. Klivansky, B. Ma, A. Navarro and Y. Liu, ACS Appl. Mater. Interfaces, 2017, 9, 20010-20019.

45 (a) B. H. Yang and S. L. Buchwald, J. Organomet. Chem., 1999, 576, 125-146; (b) J. F. Hartwig, M. Kawatsura, S. I. Hauck, K. H. Shaughnessy and L. M. Alcazar-Roman, J. Org. Chem., 1999, 64, 5575-5580.

46 A. Sakalyte, J. Simokaitiene, A. Tomkeviciene, J. Keruckas, G. Buika, J. V. Grazulevicius, V. Jankauskas, C. P. Hsu and C. H. Yang, J. Phys. Chem. C, 2011, 115, 4856-4862.

47 V. Percec, D. Schlueter, Y. K. Kwon, J. Blackwell, M. Moller and P. J. Slangen, Macromolecules, 1995, 28, 8807-8818.

48 A. González, L. Irusta, M. J. Fernández-Berridi, J. J. Iruin, T. Sierra and L. Oriol, Vib. Spectrosc., 2006, 41, 21-27.
49 E. T. Seo, R. F. Nelson, J. M. Fritsch, L. S. Marcoux, D. W. Leedy and R. N. Adams, J. Am. Chem. Soc., 1966, 88, 3498-3503.

50 K. Y. Chiu, T. X. Su, J. H. Li, T. H. Lin, G. S. Liou and S. H. Cheng, J. Electroanal. Chem., 2005, 575, 95-101.

51 R. Reynolds, L. L. Line and R. F. Nelson, J. Am. Chem. Soc., 1974, 96, 1087-1092.

52 (a) L. M. da Costa, S. R. Stoyanov, S. Gusarov, X. Tan, M. R. Gray, J. M. Stryker, R. Tykwinski, J. W. de, M. Carneiro, P. R. Seidl and A. Kovalenko, Energy Fuels, 2012, 26, 2727-2735; (b) J. Kim, J. Lee, W. Y. Kim, H. Kim, S. Lee, H. C. Lee, Y. S. Lee, M. Seo and S. Y. Kim, Nat. Commun., 2015, 6, 6959.

53 M. Pfletscher, S. Hölscher, C. Wölper, M. Mezger and M. Giese, Structure-Property Relationships in HydrogenBonded Liquid Crystals, Chem. Mater., 2017, 29, 8462-8471. 54 (a) G. A. Jeffrey, An Introduction to Hydrogen Bonding, Oxford University Press, Oxford, 1997; (b) T. Steiner, Angew. Chem., Int. Ed., 2002, 41, 48-76; (c) A. Shahi and E. J. Arunan, J. Chem. Sci., 2016, 128, 1571-1577.

55 B. C. Lin, C. P. Cheng and Z. P. M. Lao, J. Phys. Chem. A, 2003, 107, 5241-5251.

56 P. Cias, C. Slugovc and G. Gescheidt, J. Phys. Chem. A, 2011, 115, 14519-14525.

57 Y.-C. Chang, M.-Y. Kuo, C.-P. Chen, H.-F. Lu and I. Chao, J. Phys. Chem. C, 2010, 114, 11595-11601.

58 C. R. Newman, C. D. Frisbie, D. A. da Silva Filho, J. L. Brédas, P. C. Ewbank and K. R. Mann, Chem. Mater., 2004, 16, 4436-4451.

59 Y. Wang, S. R. Parkin, J. Gierschner and M. D. Watson, Org. Lett., 2008, 10, 3307-3310.

60 P. S. Davids, I. H. Campbell and D. L. Smith, J. Appl. Phys., 1997, 82, 6319-6325.

61 H. A. Al Attar and A. P. Monkman, Adv. Funct. Mater., 2006, 16, 2231-2242. 